\title{
Alberto Fuguet y la identidad on the road. El tiempo, el espacio y la identidad en el cuento "Road Story"
}

Alberto Fuguet and Identity on the road.The Time, Space and Identity in "Road Story".

Alberto Fuguet e a identidade on the road. $O$ tempo, o espaço e a identidade no conto "Road Story"

\section{Humberto Medina}

UNIVERSIDAD SIMÓN BOLIVAR, CARACAS

Profesor de Literatura del Departamento de Lengua y Literatura de la

Universidad Simón Bolívar y magíster en Literatura Latinoamericana

de la misma Universidad. Ha publicado recientemente: "La casa de las

palabras. El recuerdo y la construcción del mito en Memorias de mamá

Blanca de Teresa de la Parra" (Revista de Artes y Humanidades, 2010) y

"El juego de la duplicación original: la narrativa autorreflexiva de Ednodio

Quintero" (Núcleo, en prensa). Correo electrónico: hmedina@usb.ve 


\section{Resumen}

La obra del chileno Alberto

Fuguet está cargada

de reflexiones sobre la

contemporaneidad, la juventud

y la búsqueda de la identidad, todo ello atravesado por el funcionamiento constante del cine y los medios de comunicación. El cuento "Road Story", que aparece en su libro de relatos Cortos (2004), narra el viaje de Simón Rivas por el oeste norteamericano en búsqueda de reconstruir una identidad desestabilizada. La identidad, en este caso, no es un concepto inmutable. En "Road Story" se vuelve inestable para poner en funcionamiento las nociones de tiempo y espacio como coordenadas esenciales para su reconstrucción.

Palabras clave: Alberto Fuguet, identidad, viaje, literatura chilena, subjetividad, otredad. Palabras descriptor: Fuguet, Alberto, 1964-, identidad, literatura chilena, subjetividad, Otro (Filosofía).

\section{Abstract}

The work of the chilean author Alberto Fuguet has many reflections on the contemporary times, the youth and the search for identity, receiving, all of these, the constant influence of cinema and the media. "Road Story" is the story of Simón Rivas' journey throughout the North American West in searching of his identity. The identity, in this case, is not a stable concept. In "Road story" the idea of identity turns into an unstable concept in order to put in motion other concepts such as time and space, concepts that work as coordinates for the reconstruction of a new identity.

Keywords: Alberto Fuguet, identity, journey, Chilean literature, subjectivity, otherness. Keywords plus: Fuguet, Alberto, 1964-, identity, chilean literatura, subjetivity, other (philosophy).

\section{Resumo}

A obra do chileno Alberto

Fuguet é carregada de reflexões sobre a contemporaneidade, a juventude e a busca da identidade, todo isso atravessado pelo funcionamento constante do cinema e as mídias. $\mathrm{O}$ conto "Road Story", que aparece no seu livro de relatos Cortos (2004), narra a viagem de Simón Rivas pelo oeste norte-americano na procura de reconstruir uma identidade desestabilizada. A identidade, neste caso, não é um conceito imutável. Em "Road Story" torna-se instável para pôr em funcionamento as noções de tempo e espaço como coordenadas essenciais para sua reconstrução.

Palavras-chave: Alberto Fuguet, identidade, viagem, literatura chilena, subjetividade, alteridade. Palavras-chave descritores Fuguet, Alberto, 1964 -, identidade, literatura chilena, subjetividade, Outros (Filosofia).

RECIBIDO: 13 DE MAYO DE 2013. EVALUADO: 12 DE JUNIO DE 2013. ACEPTADO: 14 DE JUNIO DE 2013.

\section{Cómo citar este artículo:}

Medina, Humberto. "Alberto Fuguet y la identidad on the road. El tiempo, el espacio y la identidad en el cuento 'Road Story"'. Cudernos de Literatura 18.35 (2014): 259-282. 
EXISTEN DOS N OCIONES que se entraman confuerza cuando hablamos del concepto de identidad: tiempo y lugar. Efectivamente, en la construcción de una narrativa del sujeto necesariamente hay que ligar en un mismo discurso ciertos tiempos y lugares como límites dentro de los cuales tal sujeto puede inscribirse. De hecho, en buena medida, el lugar y el tiempo son categorías constitutivas del propio discurso de la identidad.

Leonor Arfuch, en El espacio biográfico, aborda el tema de la identidad como narración biográfica. En este sentido establece que la narrativa "adquiere relevancia filosófica al postular una relación posible entre el tiempo del mundo de la vida, el del relato y el de la lectura" (87). El entramado narrativo, más que ligar al sujeto a un contexto en el que se puede hacer presente, construye, como un todo, al sujeto mismo como parte fundamental del mundo de la vida. En la teoría sociológica de Habermas (1999), la noción de mundo de la vida, que viene de la fenomenología husserliana, es un concepto esencial porque se inserta en el discurso compartido de una comunidad como un trasfondo que permite la comprensión en cualquier manifestación narrativa. El lugar, el tiempo y el sujeto se entienden como aspectos simbólicos que se hacen presentes en la narración. De allí que el acercamiento que se quiere hacer en este artículo al cuento "Road Story" adquiera particular importancia. Este es un cuento que entrelaza y hace parte de su trama el problema de la identidad, del descubrimiento personal y el cuestionamiento del pasado y las raíces. Lo hace a través no solo del conflicto particular del personaje principal sino de la "puesta en escena" del cuento. Así, el espacio, la carretera y las ciudades adquieren relevancia en la historia y se convierten en un elemento al que hay que prestar particular atención.

No es ajena a la obra de Fuguet la reflexión sobre la identidad latinoamericana y las diferentes maneras en que esta se construye. Ya en el prólogo al libro de cuentos colectivo McOndo, que Alberto Fuguet editara junto con Sergio Gómez en 1996, se hace una reflexión alrededor de los cambios culturales ocurridos en América Latina y la forma en que estos cambios afectan la construcción de nuestra identidad:

El criterio de selección entonces se centró en autores con al menos una publicación existente y algo de reconocimiento local. Esta opción algo severa descalificó a ciertos autores y países de un brochazo. Exigimos, además, cuentos inéditos. Podían versar sobre cualquier cosa. Tal como se puede inferir, todo rastro de realismo mágico fue castigado con el rechazo, algo así como una venganza de lo ocurrido en Iowa.

El gran tema de la identidad latinoamericana (¿quiénes somos?) pareció dejar paso al tema de la identidad personal (¿quién soy?). Los cuentos de McOndo 
se centran en realidades individuales y privadas. Suponemos que esta es una de las herencias de la fiebre privatizadora mundial. Nos arriesgamos a señalar esto último como un signo de la literatura joven hispanoamericana, y una entrada para la lectura de este libro. Pareciera, al releer estos cuentos, que estos escritores se preocuparan menos de su contingencia pública y estuvieran retirados desde hace tiempo a sus cuarteles personales. No son frescos sociales ni sagas colectivas. Si hace unos años la disyuntiva del escritor joven estaba entre tomar el lápiz o la carabina, ahora parece que lo más angustiante para escribir es elegir entre Windows 95 o Macintosh.

La obra de Fuguet, en general, está atravesada por un acercamiento a la identidad desde las manifestaciones de la cultura industrial, como el cine, la música rock y la televisión, y el discurso juvenil. Por ello podemos hacer, por ejemplo, claras conexiones entre "Road Story" y la primera novela de Fuguet, Mala onda (1991). El personaje principal de esta novela, Matías Vicuña, un joven de 17 años que, en el Chile de los años setenta, parece vivir aislado del contexto político y a la deriva en su propia existencia, será el que, ya en los noventa, se rebelará literariamente contra el realismo mágico latinoamericano y construirá, en las posteriores novelas de Fuguet, una ciudad latinoamericana que se percibe, por un lado, desapegada del devenir político (vive en la estabilidad democrática) y, por otro, atravesada por un mundo cultural que cada vez más pierde los referentes locales y se construye en la primera ola globalizadora de los noventa. "El tiempo deviene tiempo humano en la medida en la que se articula sobre un modo narrativo y en que el relato afecta su significación plena cuando deviene una condición de la existencia temporal"' (Ricoeur 105). Como vemos, la cualidad misma de lo humano se produce en la dimensión de la narración y en su capacidad para hacer de las discontinuidades de los eventos de la realidad una continuidad discursiva y coherente. Entre Mala onda y "Road story" podemos trazar esa línea narrativa que busca primero desconstruir la identidad para encontrar, luego, nuevas formas de construirla.

Si bien desde esta perspectiva podemos abordar la idea de construcción de un discurso de la identidad, también es posible analizar los discursos en los que la identidad se vuelve inestable y se cuestiona a sí misma como consecuencia, precisamente, de un agrietamiento del plano temporal y espacial en el que se

1 Del original francés: "le temps devient temps humain dans la mesure où il est articulé ru un mode narratif, et que le récit atteint sa signification plénière quand il devient une condition de l'existence temporelle (traducción mía). 
construye el sujeto. En el ámbito de la literatura latinoamericana contemporánea, uno de los autores que con más fuerza relata en su narrativa esta inestabilidad de la identidad, por efecto del extrañamiento de sus personajes de su contexto personal y cultural, es el chileno Alberto Fuguet.

En toda la obra de Fuguet hay una aproximación constante del proceso tanto de afirmación como de cuestionamiento de la identidad. Sus historias reflejan un desplazamiento de los personajes que, en un contexto marcado por los mensajes de los medios de comunicación masivos, deben redefinirse como sujetos. En este trabajo analizaremos particularmente "Road Story", uno de los cuentos de Fuguet en los que se desarrolla de manera clara la relación entre la identidad individual y el discurso del contexto cultural. Abordaremos precisamente el papel que juegan los lugares en el proceso de pérdida/reconstrucción de la identidad y la manera en que esta también se construye como un montaje del tiempo que tiende sus puentes hacia el lenguaje cinematográfico.

\section{De lo inmutable a lo inestable}

"Road Story" aparece en el libro de relatos Cortos (2004), en el que -ya el título así lo indica- Fuguet trabaja desde la lógica y la estructura narrativa del montaje y la visualidad cinematográfica. Cortos son relatos pero a la vez son guiones, historias pensadas desde el cine, hibridaciones que desdibujan los límites del género del cuento. Según Catalina Forttes-Zalaquett, Cortos es un libro-objeto cuyos relatos

[...] resisten el nombre de cuentos [ya que] podrían ser protoguiones, diarios de viaje, crónicas, entrevistas o capítulos de novela. La amalgama de registros hace alusión a una sensibilidad y una mirada literaria que se asume interferida por el cine, la fotografía, el periodismo y los archivos colectivos de cultura pop. (139)

"Road Story" es, efectivamente, una historia de carretera, es decir, se alimenta del género cinematográfico que, principalmente en Estados Unidos, desarrolla el tema del viaje y la carretera como particular escenario en el que los personajes enfrentan sus historias personales. La premisa de la historia es sencilla: se centra en Simón Rivas, un chileno que, luego de desfalcar la compañía familiar, escapa de Chile y se va a Estados Unidos a perderse en el oeste norteamericano.

$\mathrm{Al}$ comienzo del relato hay una larga cita de la novela On the Road, de Jack Kerouac, que resulta muy importante para la lectura del cuento de Fuguet. La cita, que funciona aquí como epígrafe, acentúa la intertextualidad del cuento, que es, por demás, propia de toda la literatura de Alberto Fuguet. On the Road es un 
"fondo" simbólico que permite la comprensión del cuento así como los conceptos culturales hacen posible la construcción y comprensión del mundo de la vida. De hecho, el diálogo de Alberto Fuguet y Jack Kerouac no se da por primera vez en este cuento. Es evidente que la obra, en general, de la generación beat es una influencia muy importante en la narrativa de Fuguet. Ya en la portada de su primer libro de cuentos, Sobredosis (1990), Fuguet le hacía un guiño a Kerouac al incluir una foto del escritor norteamericano. A juicio de Adelaida Caro Martín, es el mismo Fuguet quien establece la relación entre su literatura y la de los beats, especialmente por

[...] la fascinación por Estados Unidos y por los caminos y la concepción de que la literatura no debe partir necesariamente de una élite cultural ni de círculos académicos [...] de los beat queda esencialmente la road movie, lo que constata afirmando que "viene del Quijote, es cierto, pero uno de los grandes mitos es la ruta $66 "$. (79)

La cita de Kerouac en "Road story" refiere a un discurso alienado. Son las palabras de un personaje que se encuentra perdido y extrañado del mundo $y$, también, extrañado de sí mismo. Todo él se pierde de tal forma que su propia identidad se desdibuja, se vuelve un fantasma, un extraño:

I wasn't scared; I was just somebody else, some stranger, and my whole life was a haunted life, the life of a ghost. I was halfway across America, at the dividing line between the East of my youth and the West of my future, and maybe that's why it happened right there and then, that strange red afternoon ${ }^{2} .(164)$

En la página siguiente al epígrafe comenzamos a leer la historia de Simón Rivas, quien se encuentra, al igual que el personaje de On the Road, a la deriva, en medio de la nada, metido en un paréntesis:

Simón siente que todo esto es un paréntesis. Los paréntesis son como boomerangs, cree. Incluso se parecen. Entran a tu vida de improviso y seccionan tu pasado de tu presente con un golpe seco y certero. El shock te deja mal, en una especie de terreno baldío que no es de nadie y tampoco es tuyo. Quedas a la deriva, atento y aterrado, inmóvil. (165)

2 "Yo no estaba asustado; solo era alguien más, un extraño, y toda mi vida era una vida embrujada, la vida de un fantasma. Me encontraba a mitad de camino a través de América, en la línea divisoria entre el este de mi juventud y el oeste de mi futuro, y quizás por eso ocurrió justo en ese momento y ese lugar, esa extraña tarde roja" (traducción mía). 
Tanto el epígrafe como el inicio del cuento hacen explícita la manera en que se entrelazan el lugar y la percepción del tiempo con la inestabilidad identitaria del personaje, en su proceso de extrañamiento. Los conceptos de tiempo y espacio tienen la función de ser coordenadas y "límites" para la definición de la identidad. Si las coordenadas tempoespaciales son ahora estructuras inestables que no necesariamente traen consigo un nexo concreto y material con la vida del sujeto sino que, por el contrario, pueden ser fuente de extrañamiento, entonces la propia noción de identidad se vuelve inestable.

Zygmunt Bauman reflexiona sobre la posibilidad de que, en general, el concepto mismo de frontera geofísica se relacione con las restricciones que imponen, por un lado, la medida del tiempo y, por el otro, la movilidad en el espacio: "En verdad, la 'distancia', lejos de ser objetiva, impersonal, física, 'establecida', es un producto social; su magnitud varía en función de la velocidad empleada para superarla" (21). Lo importante es establecer que tanto el tiempo como el espacio son determinantes en la experiencia del mundo vital y en el establecimiento de los territorios que elegimos llamar "nuestros"; en la conjunción del tiempo vital con el espacio fijo se encuentra la clave para la identificación de los sujetos con su lugar de pertenencia. En momentos históricos anteriores al desarrollo de los medios de comunicación modernos, podemos ver que la posibilidad de cambio social, producto de las modificaciones en la movilidad, era mínima. El tiempo del hombre estaba atado a los ciclos concretos de su propia dinámica de vida. Su ciclo vital determinaba el tiempo, no al contrario. Y el espacio en el que vivía también estaba directamente atado a su dinámica económica, por lo tanto, en épocas tradicionales es posible establecer una cierta inmutabilidad de la identidad:

La estructura social más bien rígida de las sociedades tradicionales también tiende a inhibir el individualismo. La mayoría de los campesinos no espera nunca alterar su ocupación [...]. La vida relativamente estática de la mayoría de los miembros de la sociedad tradicional constituye una barrera de protección contra la necesidad de adaptarse a gentes y situaciones a las que no se enfrentaron en la infancia, y son pocos los que poseen alguna idea de un mundo mayor al otro lado de las montañas o incluso el río. (Black 248)

La inmutabilidad de la identidad en el sujeto era posible porque el terreno sobre el que estaba construida dicha noción no permitía una proyección hacia futuro que impusiera cambios sociales importantes. Para transformar las palabras y los discursos que nos determinan como sujetos sociales, tiene que haber un impulso inicial en las propias estructuras de la sociedad; y, como lo establecen tanto Bauman como Trigo, el impulso del comercio internacional, desde las 
etapas tempranas del capitalismo, significó una transformación en la percepción espacial del mundo y un mayor dinamismo de las fronteras y los movimientos migratorios.

Trigo hace un énfasis esclarecedor en la manera en que las transformaciones en los conceptos de tiempo y espacio afectaron la memoria y la identidad. Establece que la homogeneización y la abstracción, tanto del tiempo como del espacio, produjeron un extrañamiento del sujeto de la materialidad (nexo con lo concreto) con respecto a las coordenadas que anteriormente estaban fijadas en él, como si fuesen su cuerpo: el tiempo pasa independientemente de lo que hagamos o dejemos de hacer; el mundo está allí, dinámico y cambiante, independientemente de que salgamos a él o nos encerremos en nuestras casas. Los nombres del tiempo y el espacio son el cronómetro y el mapa.

Este extrañamiento del sujeto de las coordenadas de tiempo y espacio (que ya no están más determinadas por su propia vida) supone una pérdida simbólica de aquellos lugares que representaban el arraigo a un momento de pertenencia originario (el origen, la tierra madre, la unión de tiempo y lugar), por lo que solo a través de la memoria es posible construir la identidad. Abril Trigo define este quiebre a través de la separación de los conceptos del aquí-ahora y el alláentonces.

En paradójico desplazamiento, la experiencia de la fragmentariedad desatada por la compresión del espacio y la proliferación de los no-lugares empujó a los modernistas a reconstruir la espacialidad perdida no sobre la materialidad del espacio social, sino en la temporalidad de la memoria. Esto nos trae, una vez más, al postulado inicial de que la subjetividad se constituye en la intersección del tiempo y el espacio que se consuma en la praxis social (aquí-ahora) y en el ejercicio de la memoria (entonces-allá). (329)

En "Road Story" podemos ver que Simón atraviesa una situación que le revela un nuevo estado de sí mismo. Al romper con su praxis social, de manera, además, escandalosa, ocurre el quiebre entre el devenir y el ser, vale decir, entre un tiempo y un espacio que ahora puede percibir como extrañados de sí mismo. En el relato ocurre una ruptura entre el sujeto que se estaba "haciendo" a través del trabajo, insatisfactorio en su propia empresa familiar en Chile, y la percepción que Simón tenía de sí mismo como sujeto con una interioridad inmutable (es decir, que existe dentro de ciertas coordenadas de identidad culturalmente construidas). Una suerte de nueva conciencia de sí le hace ver a Simón que la acción realizada (desfalcar la compañía y huir a Estados Unidos) le permitió fracturar el tiempo en el que vivía, un tiempo abstracto hasta cierto punto porque respondía 
a ritmos impuestos por una estructura de vida desligada de sus propios deseos. Esta fractura en la homogeneidad del tiempo le permite acercarse al pasado, ahora visible y recuperable, como memoria (el entonces-allá). Simón puede disponer de los elementos necesarios para construir una narración de sí mismo porque provocó una fisura en su escenario social y familiar concreto (Chile, el trabajo, el matrimonio fracasado) que lo mantenía olvidado en el presente. Ahora las dicotomías pasado/presente, aquí/allá, memoria/vivencia se separan por el intersticio que es él mismo como sujeto en crisis. Simón ahora puede funcionar como frontera que a la vez separa y une las coordenadas de su identidad; puede cuestionarlas y desestabilizarlas.

Ese momento de quiebre sucede en un momento anterior al relato. Recordemos que "Road Story" comienza con Simón en medio del oeste norteamericano, ya como un fugitivo. Sin embargo, en varios fragmentos de la narración podemos leer la manera en que insistentemente lucha por definirse en función de su nueva situación y de su pasado; vale decir, se pone en evidencia ese estado de devenir (becoming) que es, según Trigo, la supremacía del tiempo sobre el espacio (328). Como respuesta a ello (en la estética modernista) se produce una espacialización del tiempo (prioridad del ser), que es el proceso que vive el personaje, la búsqueda del ser en medio de la vaciedad del tiempo y el espacio abstractos:

Simón piensa que a veces piensa demasiado. Y a menudo siente que no siente nada, que todo le resbala. La gente tiende a posponer aquellos aspectos que más le cuestan. Quizás ahí estuvo su error: Simón nunca planeó nada y ahora está pagando el costo de haber vivido siempre en el presente. El problema es que su presente es igual a su pasado, y si algo no cede, el futuro no se ve promisorio. (166)

Había que quebrar la homogeneidad de su vida para descomponer el presente y el pasado y tratar de recuperar un nuevo sentido de la identidad. Tal como en el fragmento de Jack Kerouac, Simón se encuentra en la línea divisoria entre "el este de su juventud y el oeste de su futuro". En ese intersticio se descubre como habitante de un no lugar, no solo por el hecho de encontrarse realmente en un desierto, metáfora de sí mismo, sino por el carácter impersonal del contacto con el mundo exterior, siempre a través de una materialidad, de un mapa, de un símbolo del espacio:

Simón no ha tenido contacto humano real en mucho tiempo. Incluso las bombas de bencina son self-service, por lo que calcula que no ha pronunciado más de quinientas palabras en tres semanas. Simón ama los mapas. Nada le provoca más satisfacción que parar en un rest area y sacar uno de la guantera 
y comenzar a estudiarlo, inventando rutas, sumando millas, apostando por sitios desconocidos. (171)

El mapa, efectivamente, no es un detalle menor. Simón estudió cartografía, por lo que su relación con el espacio ocurre a través de los mapas. Llegar a un lugar y atravesarlo, para él, es producto de haberlo decidido, en abstracto, en un mapa "inventando rutas".

Como consecuencia de esa inestabilidad del terreno en el que se encuentra Simón, ese territorio fronterizo que entrelaza dos estados de su propia subjetividad: la memoria y la vivencia, la primera como discurso y el presente como flujo de la experiencia, el relato se desarrolla precisamente a través del recorrido del personaje por Estados Unidos, como un intento de quebrar el espacio vacío, el no lugar, para construirse un lugar de identidad. Es importante llamar la atención sobre la idea de que el paso "a través" del territorio es un gesto que pone en cuestionamiento la propia identidad, es decir, viajar a la deriva, recorrer el oeste de los Estados Unidos sin un lugar de llegada específico, huir, todos estos son actos que acentúan la necesidad de una búsqueda que necesariamente se encierra en lo íntimo, en lo personal.

Cruzar una frontera implica el riesgo de la imposibilidad del regreso: "Simón sabe que quizás ya cruzó la línea que divide la juventud del resto de su vida. Los treinta y cinco logran enviarte esa señal. Además está peligrosamente cerca de ser lo que es, no lo que quiso ser" (169). Esta imposibilidad del regreso se transfiere también al territorio, porque el viaje de Simón ocurre precisamente en la frontera entre Estados Unidos y México. Por tal razón, se puede dividir el análisis del recorrido en dos partes. La primera es la soledad, el trayecto de Simón como cuestionamiento de sí mismo en un espacio simbólico de aridez. La segunda parte es la del encuentro; Simón conoce a una mujer y con ella continúa su recorrido para llenar esos espacios vacíos con relaciones humanas concretas. Es importante en el análisis no solo el devenir de los personajes, sino la representación de los lugares/no lugares: Estados Unidos, los hoteles, la carretera, la frontera, México, los bares, etc.

\section{Agrietando el espacio}

El viaje comienza en el Gran Cañón. Allí, precisamente en una grieta socavada por el río Colorado, abrumado por el imponente espectáculo del paisaje natural, Simón siente su propia grieta y se enfrenta, a la vez, al vacío del paisaje y de su pasado:

Lo primero que hizo Simón cuando se acercó a la ribera sur del Gran Cañón fue vomitar. Simón no tiene claro si fue la altura, la atmósfera demasiado lim- 
pia, la emoción o el espectáculo de esa vista que se abre y se pierde. Cuando piensa en el Gran Cañón, Simón piensa en vértigo. Cuando piensa en su fallido matrimonio, también. (167)

Los elementos importantes en este fragmento son la geografía y su propio pasado (espacio y tiempo), como dos dimensiones que resuenan una en la otra para construir la narración de Simón. Pero los espacios que recorre (pueblos, hoteles de carretera) no están atados a él de manera concreta. Los atraviesa haciendo de ellos no lugares, con la experiencia desplazada en otro tiempo, en otra remembranza. Simón está allí, como puede estar en otro lado; lo importante es que desde donde esté puede recordar y poner en una balanza los hechos de su vida.

Simón cree que los Estados Unidos han colonizado su inconsciente. Recorriendo el Oeste, Simón siente que ha estado en lugares que le resultan familiares. Simón estudió cartografía en una universidad privada que nadie conoce o respeta. [...] Simón ha estado manejando en círculos, entrando y saliendo de un estado a otro, dejándose llevar por los nombres de los pueblos: Bisbee, Winona, Mora, Yuma, Coachella, Kayenta. Al cruzar Death Valley se detuvo en Zabriskie Point, el punto más bajo de América. (171)

Hay que establecer los parámetros de definición del no lugar para entender la relación entre el pasado y los espacios que recorre Simón. Para Marc Augé, el no lugar es el espacio que no supone una relación de identidad con el sujeto que lo habita: "Si un lugar puede definirse como lugar de identidad, relacional e histórico, un espacio que no puede definirse ni como espacio de identidad ni como relacional ni como histórico definirá un no lugar" (83). Al hablar de espacio de identidad, nos referimos a una función que le otorga el sujeto al lugar; es el sujeto quien simbólicamente puede construir un lugar como lugar de identidad. Simón se encuentra en sitios geográficos que no tienen relación con su propia historia personal, que no están atados a él de manera concreta, pero los utiliza como espacio de representación de su memoria. El personaje ha escapado de los que serían sus lugares (Chile, su hogar, su calle, su empresa), porque estando en ellos se sentía atrapado en un presente vacío; "el habitante del lugar antropológico vive la historia, no hace historia" (Augé 6o). Cuando se aleja de su lugar antropológico ocurre el quiebre que le permite hacer historia, es decir, Simón tiene que sustraerse de su lugar para escribir desde los no lugares su historia. Es desde el no lugar, desde el extrañamiento de sí mismo, que puede volver al pasado y redefinir su propia identidad. 
Es importante el hecho de que Simón atraviese espacios turísticos (Zabriskie Point, el Gran Cañón), ya representados y vaciados de cualquier historia, abiertos a ser recorridos por cualquier turista por el placer de "verse" en ellos:

El viaje $[\ldots]$ construye una relación ficticia entre mirada y paisaje. Y, si se llama "espacio" la práctica de los lugares que define específicamente el viaje, es necesario agregar también que hay espacios donde el individuo se siente como espectador sin que la naturaleza del espectáculo le importe verdaderamente. Como si la posición de espectador constituyese lo esencial del espectáculo, como si, en definitiva, el espectador en posición de espectador fuese para sí mismo su propio espectáculo. [...] El espacio del viajero sería, así, el arquetipo del no lugar. (Augé 91)

Ir a la deriva es un movimiento en el que se borran los límites de una vida segura y controlada. Ir a la deriva pone en escena una vida sin control; pero en un mundo atado por discursos controladores, quizás perderse en un recorrido sin límites seguros puede ser la recuperación de una experiencia vital, tal vez nunca totalmente libre, pero en todo caso intensa y auténtica. Al contrario, una vida segura y socialmente conformada puede hacer estallar la falsa sensación de control porque se descubre (cual golpe de boomerang para Simón) que se estaba siguiendo un camino determinado por otros. Simón se deja arrastrar por la deriva del devenir en un cuarto de hotel de California. Ve un rato televisión sin realmente ver nada, salta de un canal a otro hasta que captura una película y termina de verla. Luego se levanta y se mete en el jacuzzi y allí, sin mediar ninguna explicación, decide usar el dinero de la empresa para "vagar". Decide ponerse en marcha. ¿Qué otro sentido tiene su recorrido por lugares turísticos, aborreciendo a los turistas, si no es llamar la atención sobre el otro yo del turista (el propio Simón): el vagabundo?

Pero la frontera entre el vagabundo y el turista no es determinante en Simón. Se encuentra en un terreno que no lo define totalmente como vagabundo ni como turista. Está a la deriva, pero tiene la libertad para viajar como un turista. Está atravesando por un momento de desarraigo, pero su viaje es una expresión de libertad. Simón es una representación tanto del turista como del vagabundo. Las diferencias que establece Bauman son muy claras:

Los turistas se convierten en viajeros y privilegian los sueños agridulces de la nostalgia por el calor del hogar porque así lo desean. [...] Sin embargo no todos los viajeros se desplazan porque prefieren eso a quedarse quietos y quieren ir al lugar adonde se dirigen; muchos preferirían ir a otra parte o negarse a partir... si alguien les preguntara, pero nadie lo hace. [...] Están 
en movimiento porque fueron empujados desde atrás, después de haber sido desarraigados de un lugar que no ofrece perspectivas, por una fuerza de seducción o propulsión tan poderosa, y con frecuencia tan misteriosa, que no admite resistencia. Para ellos, su suerte es cualquier cosa menos una expresión de libertad. (121)

Simón, en todo caso, estaría en ese estado híbrido que Bauman llama semituristas/ semivagabundos (129), una mezcla de consumidor moderno que decide perderse en una travesía para fracturar una situación que se ha vuelto insoportable. El desarraigo está allí, pero la libertad también. La posibilidad de vivir, al menos por un tiempo, en un entrelugar, un intersticio que le permite la pausa, la reflexión y la construcción de nuevos lugares asociados a experiencias concretas. Esta posibilidad de crear de nuevo lugares asociados a una historia y una identidad propias se le presenta en un momento importante del texto.

Simón quiere llegar a Tucson para alojarse en el Hotel Congress:

un lugar donde vale la pena quedarse [...]. El hotel data de comienzos de siglo y sigue más o menos igual porque Tucson no es una ciudad de turistas, solo de universitarios y mexicanos que se quedaron de este lado de la frontera. (185)

El hotel funciona para él como una especie de encrucijada en la que puede reconocer a otros sujetos errantes. De alguna manera se siente cómodo allí:

Simón ama esta pieza del Congress. Podría instalarse a vivir aquí. Ya conoce a la gente que deambula por el hotel. Un viejo vaquero con botas de cocodrilo, los austriacos con look Elvis Costello, la escritora del este de Europa que toma cervezas con un huevo crudo dentro y escribe a máquina. Simón puede escuchar el tecleo desde su pieza. Son vecinos. (187)

El hotel representa un quiebre en el propio viaje de Simón, no solo porque allí conoce a la mujer que luego será su compañera de viaje, sino porque se encuentra de nuevo con Chile, pero esta vez desde la mirada "hiperreal" de un programa de turismo. El Congress se convierte en un territorio en el que Simón puede acercarse a ciertos límites culturales. Uno de ellos ocurre a través de la gente de diferentes orígenes que allí se hospeda, en este hotel que es una especie de terreno que todo lo soporta (que, aunque es un hotel histórico - así lo caracteriza Simón-, no deja de funcionar como hotel, como no lugar); pero Simón también se enfrenta a la frontera que lo une y separa de Chile, a las tensiones que suponen cuestionar su propia identidad arraigada a una tierra, a un país. Este largo fragmento es importante para entender este enfrentamiento: 
Simón, a veces, se instala a ver la tele. Una noche, después del programa de Conan O'Brian, unos chicos neozelandeses que estaban de paso cambiaron el canal y sintonizaron el canal cultural de la universidad. Por esas cosas del destino, esas cosas que cuesta creer, la estación exhibía un programa de la BBC sobre viajes. Una pareja multiétnica recorre el mundo con una mochila y cámara High-8. El país de esa noche era Chile. Mostraron Valparaíso, esas casas raras de Ritoque, de Punta Arenas. Entrevistaron a hijos de desaparecidos, a gente posmo. Después apareció el cantante Pablo Herrera y, con uno de sus dulzones temas de fondo, habló del romanticismo chilensis. Imágenes del Parque Forestal y de gente atracando en las calles. El animador dijo que en Chile la gente se besa al aire libre. Es porque todos viven con sus viejos o en sus casas están sus cónyuges oficiales, piensa Simón, pero el cantante tiene otra teoría: "Si en Chile no tienes pareja, no vales. Todos tus éxitos son nada. Eres un marginado al que no le queda otra que irse". Simón se fue a su habitación, pero no pudo dormir. Así que bajó al club donde tomó Jack Daniels con Coca-Cola y miró cómo bailaba la gente. (185-186)

Aunque Simón ha visto una mirada de Chile que atraviesa numerosos filtros culturales (es un programa inglés visto en un canal de Estados Unidos) que pudieran alejarlo de su país, es a través de este programa que se enfrenta a uno de los elementos más importantes de su propia huida: el amor y la soledad. Atado al cuestionamiento de una identidad arraigada en un país, se cuestiona la identidad también desde la perspectiva del encuentro y la convivencia con una pareja. Porque no es el país en abstracto lo que se añora, es el peso simbólico de las relaciones que se formaron: la familia, la pareja, la calle de la casa de la infancia. Allí es donde ocurre la fractura de Simón, en las relaciones. El peso de la fractura matrimonial se entiende como el enfrentamiento, ahora, de la soledad, por un lado, y la pérdida de nexos con el país de origen, por otro. Escapar usando el dinero de la empresa para vagar por Estados Unidos es terminar de violar la confianza de su propio territorio chileno (lo que quedaba como nexo: la familia), como respuesta a la traición de la que fue víctima (la infidelidad de su esposa). El enfrentamiento último es de cara a la soledad (con relación a la nacionalidad, al país, a la familia, al amor de pareja, en fin, a todo aquello que tradicionalmente define la identidad): "Podría quedarme quieto en esta pieza. Si uno es capaz de conquistar la soledad, es capaz de conquistarlo todo. De eso es de lo que uno huye, eso es lo que uno teme" (184).

En el hotel hay un momento de inflexión en la historia que le da un giro al viaje de Simón. Es el momento del encuentro con Adriana Tejada, una joven que 
se hospedaba en el Congress y que llamó la atención de Simón. A partir de este momento el viaje se transforma en una construcción de otra historia personal de Simón y otros nexos, ahora sí, atados a los lugares que visitan juntos. Pero no por ellos se rompe la tensión en el cuestionamiento de la identidad, al contrario, el encuentro supone otros enfrentamientos sobre la posibilidades de construir una narración identitaria; genera otras coordenadas que no serán ya la memoria ni el pasado sino la posibilidad del futuro.

\section{Del ocultamiento a la desnudez}

En un momento de la narración ocurre un evento trágico en el hotel. Uno de los huéspedes, la escritora de Europa del Este, se suicida. La policía llega al hotel para realizar la investigación alrededor de la muerte y es en ese momento que Simón se da cuenta de que a su visa le quedan dos meses de vigencia y toma conciencia de que debe marcharse. Se va del hotel, se va de Tucson y toma un tren con destino a Miami. Luego de una parada en Nuevo México, se duerme viendo el desierto a través de la ventana del tren, hecho que no deja de ser simbólico si pensamos en el constante cruce entre paisaje y mundo interno de los personajes: "El desierto tiene la particularidad de anular todo pensamiento. Simón, sin querer, se duerme" (194). En ese momento una mujer lo despierta y ve que Adriana Tejada está allí con él. Se presentan y Simón, luego de un breve momento de duda, le da un nombre falso, Roberto del Río. ¿Qué decir y qué no decir de sí mismo? ¿Por qué ocultarse en un juego de laberinto y falsas puertas? Simón aún está en el encierro del cuestionamiento de sí mismo desde un presente que, como él mismo ha dicho, se encuentra entre paréntesis, es decir, vaciado de contenido por un instante. Un paréntesis que puede semejar una fractura que deja un espacio para que puedan fugarse fragmentos de la memoria (como los fragmentos del cuento) que han llegado a cuestionar la propia identidad de Simón. Esas fugas le permiten preguntarse por el camino que lo ha llevado a su presente y por la tensión entre "lo que quiso ser y lo que es". Tal inestabilidad supone una sensación de inseguridad alrededor del presente. El ocultamiento, entonces, es un elemento clave, quizás, para su sobrevivencia. Adriana Tejada, aunque "vecina" del hotel, es, en principio, un elemento perturbador del viaje solitario.

A partir de este momento el control que podía tener Simón sobre su viaje y sobre sí mismo se pierde. Esa categoría que podía adjudicársele de semivagabundo/semiturista parece desplazarse hacia el vagabundo que está en movimiento porque es "empujado desde atrás" (Bauman 121). Dado que está por vencerse su visa, Simón está enfrentado al cruce entre el turista legal y aceptado en Estado Unidos y el inmigrante ilegal, suerte de paria que deambula por el país. Y 
Adriana Tejada representa esa pérdida del control, es el paso a lo ilegal. Ella, en sí misma, es la representación de una frontera para Simón que funcionará de dos maneras: la primera es llevarlo al límite, a un territorio mucho más inseguro que el territorio inicial; la segunda es (precisamente por haber llegado a tales límites) abrir la posibilidad de comprenderse desde otras coordenadas de experiencia del mundo, lo que supone para Simón una opción para construir de nuevo lugares de identidad, una suerte de nuevos lugares antropológicos desde donde pueda sentirse, al menos por un momento, más estable.

El tren ingresa a la ciudad de El Paso, que está detrás de unas paredes y lo único que se ve es Ciudad Juárez. Los ancianos del tren se asoman por la ventana y miran aterrorizados el espectáculo del Tercer Mundo que acecha a tan poco metros.

- Roberto, bajémonos. Esto está la cagada.

- ¿Qué?

- ¿Estás apurado?

- O sea, no, pero yo pensaba... Quiero ver el Álamo.

- Lo verás otro día. Podemos cruzar. Es solo un puente. Cruzás y en dos minutos estás en México.

- El otro tren pasa en dos días más.

- ¿Y? Hacemos ahora. Nos quedamos por ahí. ¿̇Acaso no estás turisteando? Un turista debe turistear. (196)

Adriana es una frontera colocada frente a Simón y, como tal, ella trae consigo una frontera real, la de Estados Unidos/México. Este es el escenario para la pérdida de control de Simón y para develar que él, a pesar de su viaje a la deriva, se encontraba aún dentro de los límites del viaje institucionalizado y controlado: tenía dinero, quería pasar por lugares turísticos (le dice a Adriana que quiere ir al Álamo), su visa estaba en orden. Adriana es el paso a lo otro, al afuera de sí mismo; y, efectivamente, el territorio que permite ese cruce es Ciudad Juárez. Cuando llegaron al borde ya anochecía y "por el Río Grande bajaba una brisa que olía a fréjoles y a petróleo quemado" (198).

Ciudad Juárez le revela a Simón una dimensión de sí mismo totalmente escondida, inexplorada, y que ninguna grieta en su presente-cuestionador-de-supasado había dejado fugar. Tendría que llegar Adriana, tendría que llegar Ciudad Juárez para que se abriera un grieta mucho más profunda por donde se fugarían, no la narración de su pasado, sino las sensaciones de un ser, todavía informe, que debía ser nombrado para que llegara a conformarse en parte de sí mismo.

Cuando llegaron al otro lado, a la Avenida Juárez, Simón sintió que estaba en otro mundo. Los olores eran otros y algo le daba miedo. Estados Unidos y, de 
alguna manera, su protegida vida allá en la tranquila comuna de Providencia, le parecían muy distantes. Esto, pensó, es el mundo real. Este era su mundo, un mundo que nunca había visto. (198)

El quiebre que ocurre en Simón ya no es solo entre su pasado y su presente, sino entre el discurso cultural y disciplinario que se extiende desde el centro de la cultura occidental y el discurso otro de la ilegalidad que se representa en Adriana y Ciudad Juárez, representación también del deseo no reprimido y la pérdida de control que siempre amenaza al poder. Simón se ubica rápidamente en la frontera control/descontrol. Ciudad Juárez y Adriana representan el evento rizomático que pone en cuestionamiento aquello que, por sí mismo, Simón no hubiese podido cuestionar.

Es precisamente en esa frontera de control/descontrol que Simón y Adriana se exponen a una serie de imágenes sexuales. En este caso, como lo establece Baudrillard en El otro por sí mismo, la imagen del sexo, la imagen explícita de sexo viene a satisfacer un deseo de realidad, no de posesión sexual en sí: "la desnudez solo sirve como intento desesperado para subrayar la existencia de algo [...] Lo sexual no es más que un ritual de transparencia" (27). En todo el fragmento de su estadía en Ciudad Juárez se desborda, más que la sexualidad, el deseo por estar en contacto con lo real más allá de las representaciones: Adriana y Simón entran en un bar "estrecho y derruido" en donde una mujer "bailaba totalmente desnuda un tema de Yuri y se introducía una botella de Corona en su vagina mal depilada" (199); "[Adriana y Simón] miraron cómo un tipo chaparrito le lamía la vulva a una chica con unos pechos enormes" (200). El cruce de la frontera, tanto simbólica como real, y el roce con la transparencia y lo real, ponen a Simón en el terreno del otro. Termina por desestabilizar la poca seguridad que podía tener en su identidad.

En la primera parte, él viaja a Estados Unidos porque las coordenadas de su tiempo y lugar no podían seguir sosteniéndose en su día a día (en ese presente continuo, suerte de olvido de sí mismo). En la narración que construye de sí hay quiebres con su territorio (Chile, su familia), todo se circunscribe a lo vivido, pero el territorio cultural se mantiene intacto (la seguridad de una vida "protegida"). Pero luego, con Adriana, la fractura es mayor porque desestabiliza los niveles más profundos del control de su discurso cultural. El enfrentamiento ya es con el deseo reprimido, con la autoridad. Simón siente miedo. Aquello que está del otro lado del borde, aquello que no puede nombrar, le produce mucha ansiedad. Le dice a Adriana que quiere "volver a la civilización" (201), al territorio de la legalidad, del sí mismo y del control. Pero quizás ya no puede 
regresar, al menos no de la misma forma. Simón ya es otro y su lucha es por nombrarse, ahora con las palabras del discurso del otro, para sentirse de nuevo habitante de una identidad. Esto se refleja en que ya no puede ser el mismo, en el cruce de frontera se enfrenta con la autoridad del oficial de inmigración y tiene que simular. Como establece Brad Epps, para pasar una frontera uno se hace pasar por alguien digno de pasarla: "Con 'hacerse pasar' quiero expresar, entre otras cosas, los actos discursivos y físicos por los cuales una persona se relaciona con otra, los actos por los cuales el 'otro' examinado pretende hacerse pasar por el mismo -o casi el mismo- que el examinador" (314). Este hecho refleja que para atravesar una frontera de control hay que plegarse al discurso controlador del centro de poder.

Simón tomó otro trago y siguió caminando. Adriana lo siguió como un perro. Cruzaron el puente y cuando llegaron al otro lado tuvieron que pasar frente al oficial de inmigración. Adriana lo abrazó y comenzó a acariciarle el vientre bajo su polera. El oficial los miró. Adriana le guiñó el ojo y, en perfecto inglés, le dijo "what a town". El tipo les respondió "you got that right" y los hizo pasar. No les pidió pasaportes ni documentos. (202)

Es un momento de simulación definitiva. Adriana entra en un juego cómplice con el oficial, como el del ciudadano norteamericano que va a México a violar las reglas que no puede violar en Estados Unidos. Para lograr un objetivo específico (pasar la frontera), ella se ubica en el terreno de quien define Estados Unidos como el territorio del orden y México como el territorio sin reglas de lo salvaje. Ella habla "en perfecto inglés", es posible que nada en su físico los delate (la madre de ella es de origen suizo y Simón, como chileno, quizás no tenga el tipo mexicano que se caricaturiza en Estados Unidos). Ella le dice con complicidad "what a town" ("iqué ciudad!") y el oficial le responde "you got that right" ("en eso tienes razón"), es decir, el oficial también ha atravesado la frontera para perderse en el territorio otro que representa México con relación a Estados Unidos. Al pasar la frontera hay una oración que no está atribuida explícitamente a Adriana o a Simón, que resalta el carácter transgresor de la simulación: "Menos mal. Porque estoy ilegal. Mi visa venció hace rato". Y luego: "Simón sintió que arribaba a una ciudad fantasma. Reinaba el silencio y los ecos. Ningún auto recorría sus estrechas calles. Los únicos peatones de la ciudad eran ellos" (202). Ellos regresan a El Paso y es como si regresaran al vacío, al desierto. De un lado el movimiento salvaje de la otredad, la exhibición y el descontrol; del otro lado, el orden que silencia y esconde. En ese tránsito Simón ha transformado su propio territorio simbólico y ahora él mismo puede pensarse y pensar el espacio (los 
lugares/los no lugares) de otra manera. Esa ciudad norteamericana (el orden) es "una ciudad fantasma".

\section{La verdad o las consecuencias}

Un nuevo momento traumático en la historia sirve como punto de inflexión para dirigir la narración hacia el final, hasta el punto en que Simón puede de nuevo construirse un terreno de estabilidad y abandonar (al menos como posibilidad) la simulación. Luego de regresar a El Paso, Simón y Adriana se registran en un hotel. Ambos están muy embriagados, pero el estado de Adriana es mucho peor que el de Simón. Entran al cuarto y ella cae dormida enseguida y él se acuesta en la cama de al lado. Al día siguiente Simón despierta primero, en plena tarde, y baja al restaurante del hotel. Cuando regresa al cuarto, Adriana está en el piso del cuarto, inconsciente y sobre un charco de sangre. Ella había bebido demasiado y, como consecuencia, había sufrido una hemorragia producto de una cirrosis. Simón enseguida pide ayuda. En el hospital, en medio de todas las preguntas de rigor para el ingreso, Simón puede finalmente descubrir datos de la identidad de Adriana, todos extraídos de sus papeles (su verdadero nombre, su estado civil, su residencia). Este aspecto es interesante porque, tal como establece Marc Augé, solo en la entrada o la salida de los no lugares los sujetos son nombrados como individuos. Se puede jugar a la simulación pero las instituciones homogeneizadoras siempre tienen acceso a los nombres y los registros que definen a los individuos. La individualización/identificación proviene de los documentos legales que delimitan el registro de la identidad. Ellos hasta ese momento habían compartido experiencias en un grado de sinceridad que los había acercado, pero se habían ocultado su nombre, su residencia, etc., aquello que está marcado en los papeles legales (pasaporte, licencia). Sabemos entonces que Adriana es Ana Cecilia Salazar Tejada, que está casada (según el pasaporte) y que residía en Bethel Park. Simón responde por los gastos del hospital. Adriana pasa cerca de dos semanas hospitalizada y Simón decide esperarla.

Luego del episodio del hospital, Simón y Adriana continúan juntos el viaje por Estados Unidos. Ella se descubre completamente ante él, solo porque en el momento del ingreso al hospital Simón puede ver sus papeles de identidad. Pero Simón sigue simulando, sigue ocultando su historia y su identidad. Le hace creer que es viudo y que trabaja en Chile en una aerolínea. Sin embargo, a pesar de la farsa, es inevitable que cada uno logre penetrar en el otro por efecto de la convivencia y de la experiencia. Los nombres, las situaciones y los referentes pierden sentido, y lo que los une son la vivencia, las sensaciones y el viaje mismo. Adriana, en un gesto de cariño y agradecimiento, le toca el rostro a Simón: "Adriana lo 
asusta pero lo tranquiliza. Le da confianza" (214). Se pone en evidencia que el contacto humano, más allá de las especificidades de los referentes (nombre, lugar de trabajo, historia), se alimenta también de una narración de sentimientos, de la posibilidad de verse atados a través de la experiencia, lo que hace que el otro se sitúe muy cerca a uno mismo. La intersubjetividad de las miradas supone no solo la conciencia del otro, sino también la conciencia de que uno mismo es el otro de alguien más. En ese juego de intercambio de perspectivas (que fue lo que vivió Simón con Adriana) pueden verse atravesadas las fronteras entre el territorio propio (el seguro) y el otro (el miedo y la ansiedad) con la posibilidad de construir un nuevo territorio:

Simón siente que, a pesar de todas las mentiras, las de ella y las de él, ya son algo así como una pareja. Simón le cree a Adriana. Eso le parece extraño. [...] Hace mucho tiempo que Simón no sentía que alguien le decía toda la verdad. $\mathrm{Y}$ eso que todo lo que dice es quizás mentira. (213)

Se dirigen finalmente a un pueblo al que Simón desea llegar, Truth or Consequences (la Verdad o las Consecuencias). El final es en extremo simbólico como llegada de un viaje de construcción de la identidad en el que Simón se ha despojado de las cargas del pasado, de aquello que dejó de parecerle propio, y que más bien le producía un efecto de extrañamiento. Llegan a un hotel que tiene un ambiente de total libertad. La mayoría de los huéspedes son europeos, todos jóvenes y universitarios. En la terraza hay varias tinas en las que casi todos están desnudos, "son muy delgados y lampiños y cuesta diferenciar a un chico de una chica" (217). Adriana está desnuda en una de las tinas. Simón se despoja de su ropa, "lo hace lento y no le es fácil" (217). Simón está desnudo, ha vuelto a sí mismo sin nada, sin pasado, sin referentes; él, solo él dispuesto a construir una identidad. Adriana ya sabe que su nombre es Simón, así que han empezado a nombrarse. La desnudez de ambos es simbólica. Él prefiere seguir llamándola Adriana y a ella no le importa (los verdaderos nombres no importan ya).

Como a lo largo de toda la historia, la relación con los lugares refleja un simbolismo significativo. Es interesante ver cómo un viaje a través de no lugares (hoteles, carreteras, hospitales), de espacios desérticos, metáforas del presente vacío de Simón, pudo abrir la posibilidad de la construcción de lugares de identidad. La identidad remozada de Simón puede hacer funcionar los lugares donde habita como lugares antropológicos, porque ambos no están total y absolutamente separados, tal como lo establece Augé:

En la realidad concreta del mundo de hoy, los lugares y los espacios, los lugares y los no lugares se entrelazan, se interpenetran. La posibilidad del 
no lugar no está nunca ausente de cualquier lugar que sea. [...] Lugares y no lugares se oponen (o se atraen) como las palabras y los conceptos que permiten describirlas. (110)

En este caso, Simón le cuenta a Adriana cómo el pueblo obtuvo su nombre, lo que es una metáfora de lo que ellos han atravesado:

Antes este pueblo se llamaba Hot Springs, pero hubo un plebiscito y decidieron cambiarle el nombre [...]. Fue por un concurso de televisión. Le pusieron el nombre del programa. No estaban contentos con el nombre, así que partieron de nuevo. (218)

Y esto es, quizás, lo importante del relato desde la perspectiva de la identidad como construcción. "Road Story" pone en evidencia las tensiones que se producen con un concepto de identidad que se alimenta, en principio, de elementos que se perciben como inmutables. Desde la inmutabilidad se piensa que la identidad es necesariamente una atadura a un país, a un nombre, a una nacionalidad, incluso a un sexo, que, en definitiva, es un accidente o una fatalidad. Pero estas nociones pueden hacerse inestables en situaciones de cruce de fronteras culturales y simbólicas. Es posible decidir ser otra cosa diferente de las inscripciones culturales e históricas. Efectivamente, tal como señala David Morley: "se han vuelto inciertos los conceptos tradicionales de hogar, lugar de origen y nación, y los paisajes electrónicos que habitamos en la actualidad se ven invadidos por todo tipo de angustias culturales, que surgen de ese flujo desestabilizador" (135).

Así como en el relato de Fuguet el pueblo decidió cambiar el nombre y empezar de nuevo, Simón decide definirse con otros parámetros. Sus nexos humanos son otros y a través de su experiencia con Adriana logró, no solo abandonar los fantasmas del pasado, sino construir lugares de identidad.

Simón se despierta. Adriana sigue durmiendo en el cuarto. Sale al aire libre. Baja a un río cercano que le recuerda el Cajón del Maipo (regreso a Chile). Los recuerdos de Natalia (su exesposa) se diluyen, y esto lo alegra. "Lo alegra tanto que se saca la argolla y la deja caer en una poza" (219). Después decide salir al pueblo y recorrer sus calles, hay mucho que conocer pero no tiene apuro. "Simón mira cómo pasan frente a él 200 motociclistas enfundados en cuero arriba de sus Harleys. Siente el viento de las motos en su cara. Simón no puede dejar de sonreír" (219).

La propia idea de movilidad en el viaje permite poner en escena las diferentes implicaciones que supone la inestabilidad del territorio sobre el que se 
construye la identidad. Quizás se pueda pensar en una construcción narrativa en diferentes planos que funcionan como fronteras. Vimos cómo Simón se desplaza en escenarios que van desde lo familiar hasta el amplio escenario de la cultura. Todo siempre nombrado desde la mirada subjetiva, porque finalmente todo nombramiento (y la identidad es un nombrar) se hace siempre desde el terreno simbólico del yo. Ahora, en la construcción de la identidad, la experiencia individual se ha vuelto un elemento relevante. "Sujeto y experiencia han vuelto", comenta Beatriz Sarlo en tiempo pasado (27). Subjetividad y relato de la experiencia son fuerzas que, en su arrastre, permiten la construcción de un discurso común; dice Sarlo: "el lenguaje libera lo mudo de la experiencia, la redime de su inmediatez o de su olvido y la convierte en comunicable, común" (29).

En efecto, lo importante, y que también se evidencia en el relato, es que la mirada subjetiva acepte la perspectiva del otro para construir un espacio común. Simón, al principio del relato, solo puede huir y desaparecer, desestabilizar su espacio de identidad. La identidad únicamente se construye en la comunidad de discursos, en este caso, Simón y Adriana se complementan como sujetos que habitan en espacios separados (sus experiencias son totalmente diferentes y su relación con su respectiva cultura es opuesta). Sin embargo, llegan a habitar uno junto al otro sin el peso de las marcas identitarias que originalmente los nombran. De hecho, marcas tan características como el nombre o la nacionalidad dejan de ser importantes en este punto de encuentro, que es un tercer espacio unido precisamente por la frontera que los separa. Nombrar es también establecer fronteras; elegir una identidad es delimitar una frontera que encierra los elementos a partir de los cuales cada individuo se define. Pero esos elementos no están encerrados como en una prisión, en principio porque sus límites tampoco son las paredes de una prisión. Son más bien membranas orgánicas que pueden adaptarse si son atravesadas por lo otro.

"Yo no estaba asustado, solo era alguien más, era un extraño", dice el narrador de On the Road. Tampoco es miedo lo que siente Simón. Es extrañamiento, extrañeza. El extrañamiento es el estado en el que el sujeto se percibe ajeno a todo discurso identitario, nada lo identifica. La identificación y la identidad provienen de reconocerse en otro/idéntico, un otro que habla de mí y me interpela solo con su presencia.

"Road Story" es un relato que aborda los conflictos de la construcción de la identidad desde el viaje y el cruce de fronteras. Es una reflexión sobre el pasado (el tiempo) a través del viaje y el territorio (el espacio). Simón vuelve a la estabilidad y al encuentro de sí por medio de su recorrido (por los lugares que se reinstituyen como lugares de identidad) y de Adriana como personaje que 
representa la imagen refleja de Simón. Los fragmentos del cuento, los trozos de narraciones que aparecen como breves escenas de una película, acentúan, efectivamente, el carácter fragmentado de Simón, el carácter fragmentado de todo relato, el carácter discontinuo de todo relato identitario que implica, necesariamente, la presencia del otro para su construcción coherente. Porque todo relato de identidad, finalmente, lleva implícito un diálogo.

\section{Obras citadas}

Arfuch, Leonor. El espacio biográfico. Dilemas de la subjetividad contemporánea. México: Fondo de Cultura Económica, 2007.

Augé, Marc. "El lugar antropológico. De los lugares a los no lugares". Los no lugares. Espacios del anonimato. Una antropología de la sobremodernidad. Barcelona: Gedisa, 1993. 62-93.

Baudrillard, Jean. Cultura y simulacro. Barcelona: Kairós, 1978.

- El otro por sí mismo. Barcelona: Anagrama, 1988.

Bauman, Zygmunt. La globalización. Consecuencias humanas.

México: Fondo de Cultura Económica, 1998.

Black, Cyril. "La dinámica de la modernización: un repaso general". Cambio social. Por R. Nisbet et al. Madrid: Alianza, 1979. 226-256.

Caro Martín, Adelaida. América te lo he dado todo y ahora no soy nada: contracultura y cultura pop norteamericanas en la narrativa de Ray Loriga y Alberto Fuguet. Berlín: Universität Göttingen, 2007.

Epps, Brad. "Actas y actos de inmigración". Nuevas perspectivas desde/sobre América Latina: el desafío de los estudios culturales. Ed. Mabel Moraña. Pittsburgh: Instituto Internacional de Literatura Iberoamericana, 2001. 261-272. Fuguet, Alberto. Mala onda. Santiago de Chile: Alfaguara, 1996.

— "I'm not a Magic Realist". www.Salon.com (revista electrónica). 11 de junio de 1997. Abril de 2012. Web. <http://www.salon.com/june97/magical970611.html>.

_ "Road Story". Cortos. Santiago de Chile: Alfaguara, 2004. 163-219.

- Sobredosis. Santiago de Chile: Punto de Lectura, 2005.

- Apuntes autistas. Santiago de Chile: Aguilar, 2007.

Fuguet, Alberto y Sergio Gómez, ed. McOndo. Barcelona: Grijalbo-

Mondadori, 1996. Abril de 2012. Web. <www.mml.cam.

ac.uk/spanish/sp13/popculture/pre-mcondo.pdf $>$.

Habermas, Jürgen. Teoría de la acción comunicativa. 2 tomos. Madrid: Taurus, 1999.

Morley, David. "Belongings. Place, Space and Identity in a Mediated World". European fournal of Cultural Studies (Londres) 4 (2001). 425-448

Ricoeur, Paul. Temps et récit 1. Lintrigue et le récit historique. París: Seuil, 1983. 
Sarlo, Beatriz. Tiempo pasado. Cultura de la memoria y giro subjetivo. Una discusión. Buenos Aires: Siglo XXI, 2007.

Trigo, Abril. "Migrancia: memoria: modernidá". Nuevas perspectivas desde/ sobre América Latina: el desafío de los estudios culturales. Ed. Mabel Moraña. Pittsburgh: Instituto Internacional de Literatura Iberoamericana, 2001. 273-291.

\section{Bibliografía sobre Alberto Fuguet}

Decante, Stéphanie. "Del valor material al valor simbólico: tensiones y negociaciones con el horizonte de expectativas en el Chile de los 9o. El "caso Fuguet"'. Arizona fournal of Hispanic Studies 9 (2005): 181-191.

Forttes-Zalaquett, Catalina. "Cortos de Alberto Fuguet: diagnóstico fronterizo para un perdido". Hipertexto 9 (2009, invierno): 139-146.

Hernández, Heriberto. "Exceso, pirateo y retrospección subjetiva en Por favor, rebobinar". Espéculo (Universidad Complutense de Madrid) 38 (2008, marzo junio). Abril de 2012. Web. <http://www.ucm.es/info/especulo/numero38/afuguet.html>.

O'Connell, Patrick. "Santiago's Children of the Dictatorship: Anamnesis versus Amnesia in Alberto Fuguet Por favor, rebobinar. Narrating History through Memory in Three Novels of Post-Pinochet Chile". Hispania 84.2 (2001): 181-192.

Pasten, Agustin. "Neither Globalized nor Glocalized: Fuguet's or Lemebel's Metropolis?". AmeriQuest 2.1 (2005). 117-133. 